Revista Destaques Acadêmicos, Lajeado, v. 10, n. 4, 2018. ISSN 2176-3070

DOI: http://dx.doi.org/10.22410/issn.2176-3070.v10i4a2018.2037

http://www.univates.br/revistas

\title{
FINDWAY: APLICATIVO PARA AUXILIAR A MOBILIDADE EM AMBIENTES INDOOR
}

\author{
Murilo Schonarth ${ }^{1}$, Fabrício Pretto ${ }^{2}$
}

Resumo: Os ambientes indoor apresentam problemas quanto a mobilidade devido à dificuldade das pessoas localizarem-se. Vastos corredores formados por um grande número de salas, prejudicam a localização dos ambientes desejados pelos usuários destes locais. O presente trabalho foi elaborado com o objetivo de minimizar o problema da mobilidade dos ambientes indoor, através do desenvolvimento de um aplicativo para Smartphones e Tablets que utilizam a plataforma Android. A solução desenvolvida possibilita acessar os mapas do ambiente e receber orientações de localização, exibindo um sistema Wayfinding por setas que indica as direções a serem tomadas pelo usuário durante sua locomoção. Para compreender as técnicas e as opções utilizadas no desenvolvimento é exibido um estudo sobre os tipos de sinalização utilizados para localização e mobilidade, e sobre as técnicas de localização. Além do estudo, é demonstrado o projeto elaborado para o aplicativo, sendo exibidos modelos para compreender o funcionamento da ferramenta, seus requisitos, entre outros, o processo de desenvolvimento e a validação do experimento realizado.

Palavras chave: Sinalização. Wayfinding. Aplicativo Android. Localização.

\section{INTRODUÇÃO}

Ao visitar lugares desconhecidos, é comum que as pessoas fiquem confusas em relação à distribuição dos seus espaços. Com isso, é possível que elas tenham dificuldade de encontrar as direções que devem ser tomadas para deslocar-se pelo local, principalmente quando não há existência de um sistema de sinalização que repasse instruções de mobilidade deste lugar. Estas dificuldades encontradas, são vistas principalmente em ambientes complexos, podendo eles ser abertos ou fechados.

Como exemplo pode-se citar um aeroporto, que conta com espaços outdoor e indoor, como a pista de decolagem e pouso e o saguão com lojas e

1 Graduado em Sistemas de Informação - Univates

2 Mestre em Ciência da Computação - Professor - Univates 
lanchonetes, assim como o campus de uma universidade, que possui as salas de aula, e uma área outdoor, onde estão inúmeros prédios espalhados por ela. Estes dois exemplos são considerados ambientes grandes e bem complexos, pois ambos possuem uma área extensa, com espaços ocupados em todos os seus cantos, onde na maioria das vezes um setor ou um grupo de prédios, ficam distantes dos demais.

Por ser inevitável a existência de lugares amplos, sejam eles indoor ou outdoor, a localização torna-se um problema. Placas, setores identificados por cores, sinais luminosos e sonoros, entre outras formas de sinalização, tentam orientar as pessoas, repassando informações e sinais importantes, para que seja facilitada a mobilidade no local. Estes, são itens muito importantes para um ambiente complexo, pois seus usuários necessitam destas informações repassadas por eles para se localizarem com mais facilidade.

Com o avanço da tecnologia, os utensílios e serviços utilizados para a orientação e localização tiveram diversas melhorias, possibilitando o surgimento de novas técnicas na utilização dos mesmos. Esta enorme evolução, permitiu a inclusão de algumas ferramentas de localização em dispositivos móveis, como os Smartphones, fazendo com que eles sejam utilizados com maior frequência que os demais equipamentos de localização e orientação que já existiam.

Uma das muitas tarefas em que estes dispositivos podem auxiliar, é a localização e orientação em ambientes complexos, tanto outdoor como indoor. Isto se dá graças às tecnologias existentes que possibilitam o auxílio desta função, tendo em vista que os frequentadores do local não conheçam sua estrutura ou não a dominam por completo.

Com a intenção de auxiliar na mobilidade destes ambientes, este trabalho visa apresentar o desenvolvimento de um aplicativo para dispositivos móveis (Smartphones e Tablets), utilizando a plataforma Android. Esta ferramenta, permite ao usuário acessar os mapas dos locais, sejam eles outdoor ou indoor, exibindo um sistema wayfinding, possibilitando a localização de salas, prédios, entre outros e oferecendo orientações a pessoa que for utilizá-lo, para encontrar um destino no ambiente que o aplicativo for aplicado.

\section{FUNDAMENTAÇÃO TEÓRICA}

Neste capítulo é exibida a fundamentação teórica sobre as técnicas e tecnologias utilizadas no desenvolvimento da pesquisa.

\subsection{Sinalização}

A sinalização pode ser usada de diferentes formas e métodos e em diversas situações e ambientes, referindo-se a algo explicativo que mostre alguma orientação, direção ou informação, ajudando a organizar locais grandes e complexos, através de setas, placas, entre outras formas. Ela deve informar sobre algo que os usuários procuram e após confirmar esta informação. Desta 
forma seu principal objetivo é sinalizar algum local ou ambiente, fornecer informações aos usuários não frequentes, àqueles que não têm o domínio do espaço ou ambiente. A sua missão é tornar a visita do novo usuário o mais confortável possível (CHAMMA; PASTORELO, 2007). Como exemplo de sinalização é possível citar a sinalização por cores, sinalização vertical e horizontal, por palavras, entre outros tipos.

\subsection{Ambientes indoor e outdoor}

Os ambientes podem ser divididos em duas áreas: indoor e outdoor. Os ambientes indoor, correspondem às áreas fechadas, ou seja, que ficam na parte interna de edifícios, túneis, entre outros, e os outdoor representam os locais abertos, como ruas e avenidas, por exemplo. A dificuldade de obtenção da localização nos ambientes indoor é consideravelmente mais elevada, pois nestes locais não há equipamento dedicado, como acontece com a localização outdoor, que conta com o GPS (GATTERMANN, 2013).

\subsection{Wayfinding}

$\mathrm{O}$ wayfinding refere-se a sistemas de informação que orientam as pessoas de um ambiente físico e melhoram a sua compreensão e experiência no espaço. Este sistema de orientação é particularmente importante em ambientes complexos, como centros urbanos e campos educacionais. Como a locomoção e localização em ambientes arquitetônicos está cada vez mais complexa, as pessoas necessitam de pistas visuais, como mapas, rotas e símbolos para ajudar a guiá-los até seus destinos. Nestes ambientes, sistemas de wayfinding eficazes contribuem para uma sensação de bem-estar, proteção e segurança (SEGD, 2016).

Segundo Pezzin (apud BAUMANN, 2013), a finalidade do wayfinding é orientar as pessoas sobre o entorno de um ambiente construído não familiar, além de ser indispensável para mostrar informações em locais estratégicos e instruir as pessoas na direção correta.

O wayfinding exige uma habilidade de conhecimento que pode ser muito simplificada com a sinalização em áreas estratégicas, no local a ser explorado. Por isso, sua principal atenção está na elaboração e organização de mapas e diagramas, além da previsão do fluxo dos diferentes tipos de frequentadores do ambiente. Para que o usuário possa ter maior independência é interessante não apenas que ele possa ler e compreender os sinais, mas que possa circular pelo local e idealizar mapas mentais no espaço em questão com segurança. É importante que o ambiente tenha sequencialidade e redundância da informação e da linguagem utilizada, nos momentos corretos, a fim de simplificar o reconhecimento ou memorização das informações do ambiente (PEZZIN, 2013). 


\subsection{Grafos}

Utilizados muito na matemática e em estruturas de dados de programação, os grafos formam-se através de um par $\mathrm{V}$ e $\mathrm{A}$, onde $\mathrm{V}$ são um conjunto de elementos chamados de vértices e $\mathrm{A}$ chamado de arestas. As arestas interligam dois vértices e dois vértices ligados por uma mesma aresta são chamados de vértices adjacentes. Para a exibição gráfica de um grafo são determinados pontos distintos para representar os vértices e uma linha para unir dois pontos para representar a aresta. Em alguns casos a linha utilizada para representar uma aresta é substituída por uma seta, neste caso o grafo é considerado dirigido e quando não possui a seta, é definido como não dirigido.

Existem algumas formas para percorrer os grafos, como os percursos que são uma sequência de vértices do ponto inicial até o final, onde o comprimento do percurso é o número de arestas que deve-se percorrer para chegar até o fim do grafo, por exemplo: em um grafo com os vértices $A, B$ e $C$, onde o ponto inicial é A e o final $C$, o comprimento é dois, pois para se chegar até $C$, deve se passar pela aresta de A até B e de B até $C$, ou seja, é preciso passar por duas arestas para se chegar ao ponto final. Outra forma de percorrer um grafo é escolhendo o caminho com o menor peso, onde define-se pesos para as arestas que ligam um vértice ao outro, permitindo somar o peso total de um caminho, possibilitando a escolha do caminho com o menor peso (COSTA, 2011).

\section{METODOLOGIA}

De acordo com os objetivos propostos, o tipo de pesquisa realizada pode ser considerada exploratória, onde um dos seus objetivos é compreender a mobilidade de ambientes complexos através das funcionalidades da ferramenta implementada. O autor GIL (2002, p. 41) cita que:

O objetivo da pesquisa exploratória é proporcionar maior familiaridade com o problema, com vistas a torná-lo mais explícito ou a constituir hipóteses, onde o seu principal objetivo é o aprimoramento de ideias ou a descoberta de intuições.

Além de ser exploratória, a pesquisa também pode ser considerada como experimental, pois um de seus objetivos é desenvolver o aplicativo, o que se caracteriza como um experimento. Para GIL (2002), a pesquisa experimental é quando se determina um objeto de estudo, identificando e tratando o que seria capaz de influenciá-lo de forma que seja possível definir as formas de como gerenciar e verificar estas influências.

Primeiramente realizou-se uma pesquisa exploratória sobre as soluções existentes no mercado que auxiliem a mobilidade em ambientes complexos, onde foram encontrados alguns aplicativos similares ao proposto neste trabalho. Em todos os casos, as ferramentas continham algum tipo de comunicação para apoiar a tarefa de localização, tais como GPS e Bluetooth. 
Com base na pesquisa realizada, definiu-se o escopo do projeto. Definiu-se que o aplicativo deva ser desenvolvido para dispositivos móveis que utilizem a plataforma Android, onde seu principal objetivo é auxiliar os usuários a encontrarem destinos, utilizando um sistema de wayfinding disponibilizado sobre o mapa do local. A forma do usuário identificar seu local atual e coletar informações, é realizada por imagens QR Code com informações de localização. Em concomitância, foram realizadas algumas pesquisas para construir a fundamentação teórica, onde são abordados e definidos os temas utilizados ao longo do trabalho.

Com boa parte da fundamentação teórica concluída foi possível dar início ao desenvolvimento da proposta, onde foram definidas as funcionalidades que o software iria possuir e as técnicas envolvidas. Primeiro, foram levantados todos os requisitos fundamentais e em seguida deu-se a elaboração de alguns modelos necessários para melhor compreender como funcionaria a ferramenta.

Após a elaboração da proposta começou o processo de desenvolvimento da ferramenta, que envolveu a programação do aplicativo, a montagem dos mapas dos ambientes indoor e outdoor e o cadastro das informações de ambos os ambientes. Depois da conclusão do desenvolvimento da ferramenta foi realizada uma validação com alguns usuários, onde o aplicativo foi utilizado pelos voluntários para o teste. O principal objetivo desta validação, foi verificar o funcionamento da ferramenta, testando todas as suas funcionalidades, principalmente as orientações que ele fornece ao usuário para que ele consiga encontrar o seu destino.

\section{DESENVOLVIMENTO DA SOLUÇÃO}

O principal objetivo do aplicativo FindWay é auxiliar na mobilidade em ambientes complexos outdoor e principalmente indoor, através de um sistema de wayfinding, sem qualquer necessidade de comunicação para localizar-se, como GPS ou Wi-Fi, por exemplo. Para contar com as informações atualizadas do local em que se pretende utilizar a ferramenta, o aplicativo necessita do auxílio de uma aplicação web, que será um painel administrativo que alimenta os dados necessários para o funcionamento do software, sendo adquiridos para o dispositivo através de uma ação do usuário no aplicativo, onde é necessário a comunicação com a Internet. Este painel administrativo não foi desenvolvido e pode ser simulado por um banco de dados com as informações necessárias, pois o foco do presente trabalho é o desenvolvimento do aplicativo.

Para conseguir auxiliar os usuários corretamente é necessário que se conheça a localização atual no ambiente, para isso é preciso que sejam disponibilizados checkpoints pelo local por meio de QR Codes, contendo as informações de localização, para que o sistema consiga obter a posição atual do usuário através da leitura dos códigos com um Smartphone. Após a leitura, o utilizador do software em questão pode visualizar a representação gráfica 
do local com uma figura sinalizando a localização obtida através do QR Code. Caso a localização seja outdoor, são exibidos juntamente todos os prédios existentes separados por setores, e caso seja indoor é apresentado o andar do prédio em que o checkpoint se encontra, as salas e demais componentes deste local. O usuário, quando conhecer sua localização, pode informar ao software onde ele está.

Quando a localização atual for em um ambiente indoor são exibidos todos os checkpoints disponíveis para consulta naquele local. Nos ambientes outdoor estes pontos de consulta não são exibidos, pois em alguns testes realizados com a ferramenta constatou-se que com um grande número de prédios o mapa do local oferece muitas informações, dificultando a identificação dos prédios.

Antes ou após obter ou informar a localização, é possível inserir um local como destino para obter orientações de como chegar a ele. A ferramenta não traça uma rota para o destino desejado, mas apresenta as direções que devem ser tomadas para chegar até ele, através de setas sobre a representação gráfica do local entre os prédios ou salas.

\subsection{Organização do ambiente}

Para o desenvolvimento do protótipo o local adotado foi o campus da Univates e desta forma é preciso que o aplicativo consiga estruturar os dados do ambiente. Para isso, a ferramenta utilizou a divisão do campus que a própria Univates utiliza, onde o local é dividido em quatro setores, denominados como A, B, C e D, onde o setor A é representado pela cor azul, o B por Laranja, o C por vermelho e o setor $\mathrm{D}$ pela cor verde. Na parte A do campus, estão os prédios um até o local onde existe um lago, no B os prédios onze até a biblioteca, no $\mathrm{C}$ os prédios dezesseis até o centro clínico e na parte $\mathrm{D}$ os prédios dezessete até o vinte e dois.

A partir desta divisão do campus é montada a estrutura de dados do aplicativo e para isso foi utilizado a teoria de grafos, desta forma a parte outdoor do campus forma um grande grafo, onde cada prédio é um nodo do grafo. Os ambientes indoor, como um andar de um prédio por exemplo, formam um outro grafo, pois são utilizados grafos diferentes para cada um dos ambientes indoor, porque não é possível criar subgrafos, ou seja, cada ambiente indoor possui um grafo para a sua estrutura e neste caso os nodos são as salas.

\subsection{QR Codes}

Em ambos os ambientes que a ferramenta é utilizada, seja indoor ou outdoor, deve-se ter alguns QR Codes espalhados por sua estrutura para que seja possível localizar-se. Nos locais outdoor, todos os prédios possuem em suas entradas ao menos um checkpoint disponível e nos indoor somente algumas salas contam com os pontos para consulta, pois o ambiente não necessita de tantos pontos. Nos mapas indoor, as salas que possuem um checkpoint são sinalizadas 
sobre o mapa com a figura de um QR Code. Estes QR Codes espalhados pelo local onde o software é utilizado, possuem a informação que possibilita o aplicativo de encontrar a localização atual do usuário por meio da sua leitura com o aplicativo leitor de QR Codes Bar Code Scanner que deve estar instalado no Smartphone utilizado.

Os QR Codes possuem duas informações, que são o tipo do local onde o usuário está, indoor ou outdoor, e o código do local cadastrado no banco de dados. Estas duas informações são separadas através de um caractere ' $\wedge$ ', possibilitando a obtenção das informações separadas facilmente por sua posição no texto, ou seja, o que vem antes do caractere separador fica na posição 1 e o que fica depois, na posição 2, por exemplo: no QR Code disponível na entrada do prédio 2 , a informação lida é $\mathrm{P}^{\wedge} 2$, onde a posição 1 é o ' $\mathrm{P}^{\prime}$ que se refere a prédios e a posição dois é o código do prédio cadastrado no banco de dados. A informação para uma sala seria $\mathrm{SL}^{\wedge} 1$, onde o 'SL' indica que o usuário está em frente a uma sala e o 1 é o código cadastrado no bando de dados.

Para realizar a leitura dos QR Codes o aplicativo FindWay utiliza a ferramenta Bar Code Scanner para ler os QR Codes disponíveis no ambiente, onde o software de leitura deve estar instalado no Smartphone utilizado e caso não esteja, o próprio aplicativo direciona o usuário para realizar a instalação no dispositivo.

\subsection{Problema do caminho mínimo}

Para resolver o problema do caminho mínimo o software possui em seu banco de dados informações numéricas que utilizam pesos de 1 a 5 e servem para representar a distância entre dois pontos, onde pontos próximos recebem um peso menor e pontos distantes recebem um peso maior, por exemplo: entre os prédios 1 e 3 o peso definido é 2 e entre os prédios 2 e 3 o peso é 1 , com isso percebe-se que o Prédio 3 fica mais próximo do prédio 2 em comparação com o prédio 1.

Com estas informações o aplicativo consegue obter o menor caminho para chegar a ao destino escolhido utilizando um método recursivo que encontra todas as possibilidades existentes de se chegar ao ponto final. Uma função que utiliza recursividade é uma rotina útil e muito poderosa, pois ela permite chamar a si mesma direta ou indiretamente, ou seja, ela é chamada de recursiva quando possui ao menos uma chamada a si própria, de modo que execute o mesmo trecho de código utilizando novas possibilidades (DEVFURIA apud SANTOS, 2017).

Juntamente com os caminhos encontrados, o algoritmo guarda o peso total do ponto inicial até o ponto final. Após encontrar todas as possibilidades de caminhos existentes, o software verifica o percurso com o menor peso total e exibe para o usuário sobre o mapa através das setas entre dois pontos. 


\subsection{Interfaces}

Nesta seção são apresentadas as interfaces do aplicativo, juntamente com o seu detalhamento. Na Figura 1 é exibida a tela de menu, que é a interface inicial e onde estão dispostas as funcionalidades que podem ser acessadas diretamente pelo usuário, sem depender de alguma informação, são elas:

a) Definir localização: Quando for escolhida esta opção o aplicativo oferece duas formas para o usuário se localizar, uma é através da leitura de um checkpoint e a outra por meio da escolha de um local em uma lista exibida. Quando escolhida a opção de leitura de um checkpoint, o sistema ativa a ferramenta BarCode Scanner para que ela leia o QR Code e retorne as informações que constam nele. Quando a opção escolhida for definir a localização por meio das listas, o software exibe a mesma tela que é mostrada ao pressionar o botão 'Definir destino', oferecendo os mesmos tipos de localização, prédios e salas, para que seja definida a posição atual no ambiente, por meio da escolha do local em uma lista com todos os cadastros do sistema. Após a definição, é exibido o mapa com a localização atual marcada sobre ele, através de uma imagem.

b) Definir destino: Quando ativado este botão, o sistema oferece duas opções de tipos de destinos, que são os prédios e as salas. Após a escolha do tipo de destino é exibido para o usuário uma lista de todos os locais cadastrados no banco de dados, de acordo com o tipo escolhido anteriormente, para que o usuário escolha o destino que deseja. Após esta escolha, ele deve localizarse através da leitura de um checkpoint ou definindo sua posição atual e então, solicitar as orientações de como chegar no local procurado.

c) Visualizar mapa: Ao tocar neste botão o aplicativo exibe duas opções de mapa, que são os mapas dos setores, ou seja, os mapas outdoor, e os mapas dos andares. Quando for escolhida a visualização dos mapas dos setores são exibidos todos os mapas outdoor do local, sendo divididos por seus setores. Já a opção de visualizar os mapas dos andares, o usuário deve selecionar o prédio e o andar que deseja visualizar através de uma lista exibida. Após a escolha o aplicativo exibe o mapa do andar sinalizando os checkpoints existentes no andar.

d) Sincronizar: Quando o painel administrativo web estiver disponível, ao pressionar este botão, a ferramenta deve sincronizar os dados e os mapas com o painel administrativo web. Está opção não foi desenvolvida pois o painel administrativo foi simulado por um banco de dados.

Ao conhecer a posição atual do usuário, por meio do escaneamento de uma imagem ou por definição através das listas de locais apresentadas, o sistema exibe o mapa do ambiente sinalizando a localização atual com algumas marcações sobre ele. Quando o mapa é de um local indoor são sinalizados todos os checkpoints disponíveis para consulta por meio de uma imagem de um QR Code em frente ao local que está a imagem no ambiente físico. Sobre os mapas indoor estão sinalizados, através de uma figura, os banheiros, feminino e masculino, as escadas e o elevador, sendo estas marcações fixas na imagem 
do mapa. A Figura 2 apresenta a simulação da leitura de um checkpoint que contém as informações da sala 201 no segundo andar do prédio 11, onde notase a exibição dos QR Codes para sinalizar onde estão os pontos de consulta no andar, uma figura de um boneco para sinalizar a localização atual e as imagens para identificar a posição dos banheiros, da escada e do elevador. Na Figura também é exibida a descrição da sala do checkpoint lido, o prédio e o andar que o usuário se encontra.

Figura 1 - Tela de menu

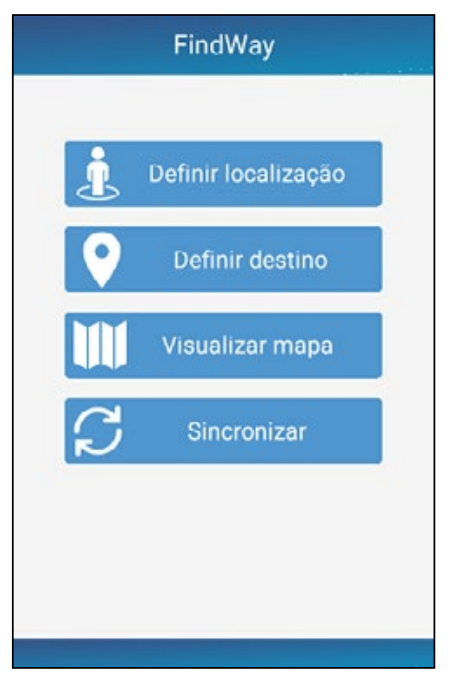

Fonte: Elaborado pelo autor (2017).

Figura 2 - Exibição de um mapa indoor

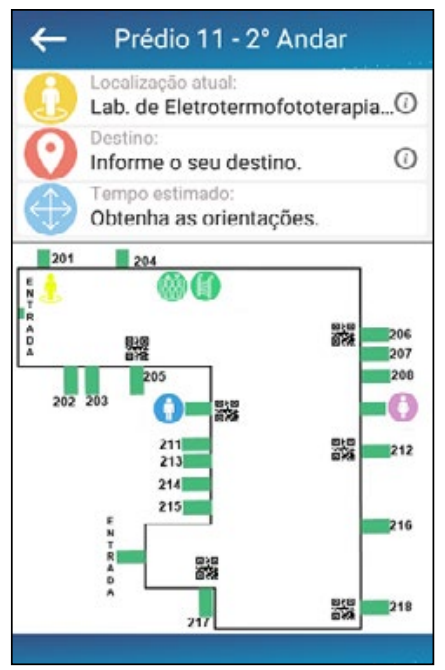

Fonte: Elaborado pelo autor (2017). 
Nos mapas dos ambientes outdoor também são exibidas algumas sinalizações sobre eles, como o número dos prédios, por exemplo. Porém, não são exibidos os checkpoints disponíveis para consulta, pois a exibição destas figuras sobre o mapa dificulta a compreensão do mesmo. O que muda em relação aos mapas indoor, além de não exibir os pontos de consulta, é que nos outdoor são carregados todos os mapas para a tela, separados por setores, ou seja, cada setor possui um mapa, onde eles são exibidos separadamente. Para exibir os mapas o usuário deve rolar o mapa para direita ou para esquerda. A Figura 3 mostra a exibição do mapa de um ambiente outdoor, exibido após a leitura de um QR Code que contém as informações referentes ao prédio $3 . \mathrm{Na}$ Figura é exibido a localização atual, da mesma forma dos ambientes indoor, o setor onde o usuário está e o prédio ao qual foi consultado o checkpoint, e no topo do mapa a informação de qual mapa está sendo exibido e a quantidade de mapas disponíveis no ambiente.

Figura 3 - Exibição de um mapa outdoor

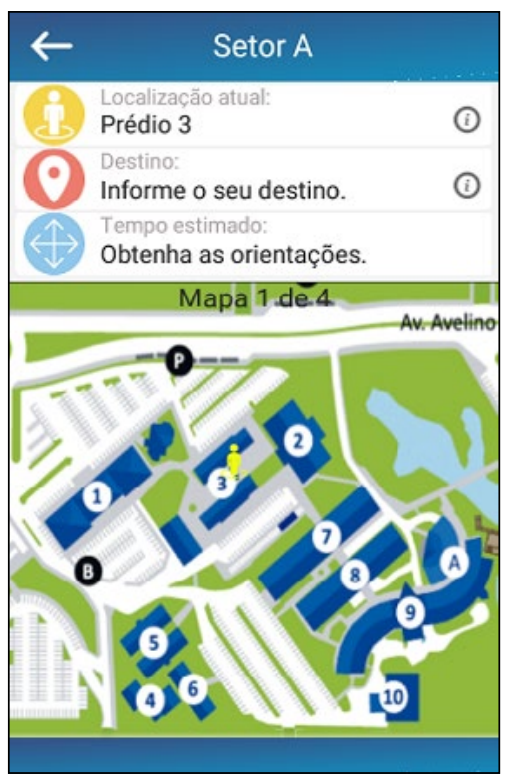

Fonte: Elaborado pelo autor (2017).

Após a exibição do mapa com a posição atual sinalizada sobre ele, o usuário pode escolher o destino que deseja obter orientações e para isso ele deve pressionar o botão vermelho na lateral esquerda superior. Caso o local escolhido seja no mesmo ambiente que a localização atual, o destino é marcado sobre o mapa com a mesma figura apresentada no botão pressionado para definir o destino. Na Figura 4 é exibido a sinalização do destino escolhido, onde a imagem A apresenta como destino à sala 212 no segundo andar do prédio 11 
e na B o prédio 9, onde a descrição do local é exibida ao lado do botão utilizado para a escolha do destino.

Figura 4 - Destinos definidos

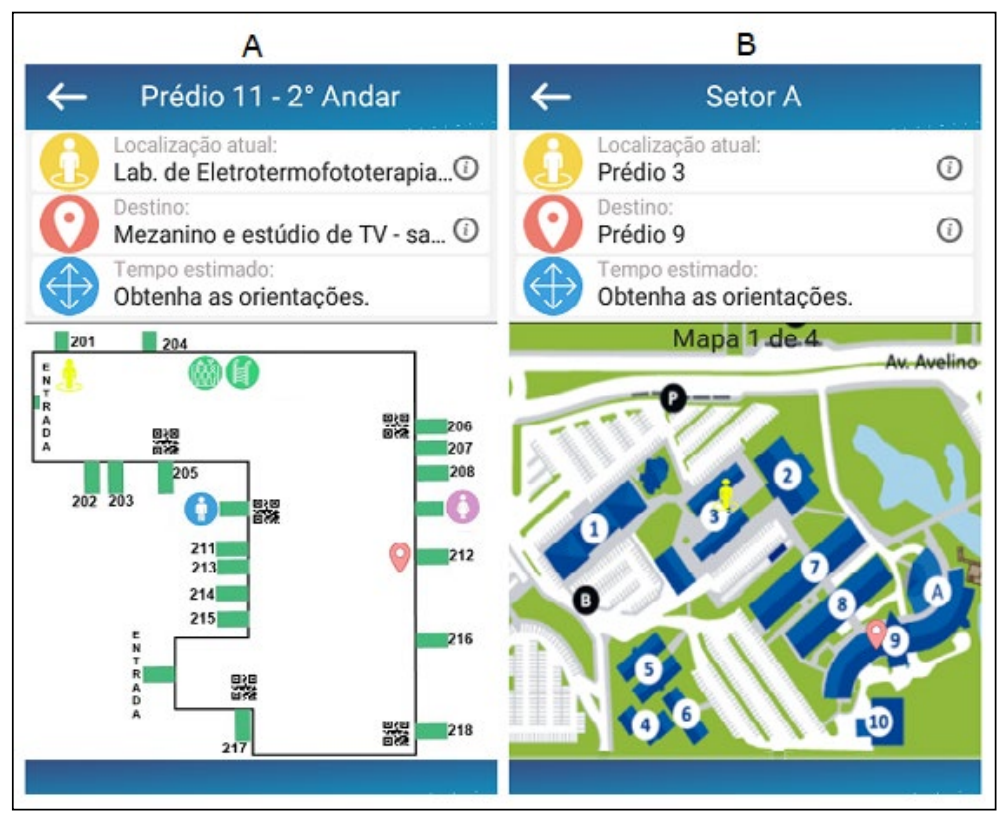

Fonte: Elaborado pelo autor (2017).

Após ter a localização atual e o destino definido, o usuário do aplicativo FindWay pode solicitar as orientações de como chegar ao local escolhido. Quando solicitada a orientação pelo usuário, o aplicativo executa o algoritmo de caminho mínimo para obter as orientações que deve exibir. Ao obtê-las, são exibidas algumas setas sobre o mapa para informar quem está utilizando a ferramenta as direções que devem ser tomadas para chegar ao destino. A Figura 5 mostra as orientações fornecidas em ambos ambientes, onde a imagem A apresenta um mapa indoor e a B um outdoor, ambos utilizando as localizações e os destinos utilizados na Figura 4, exibida anteriormente. 
Figura 5 - Orientações fornecidas pelo aplicativo

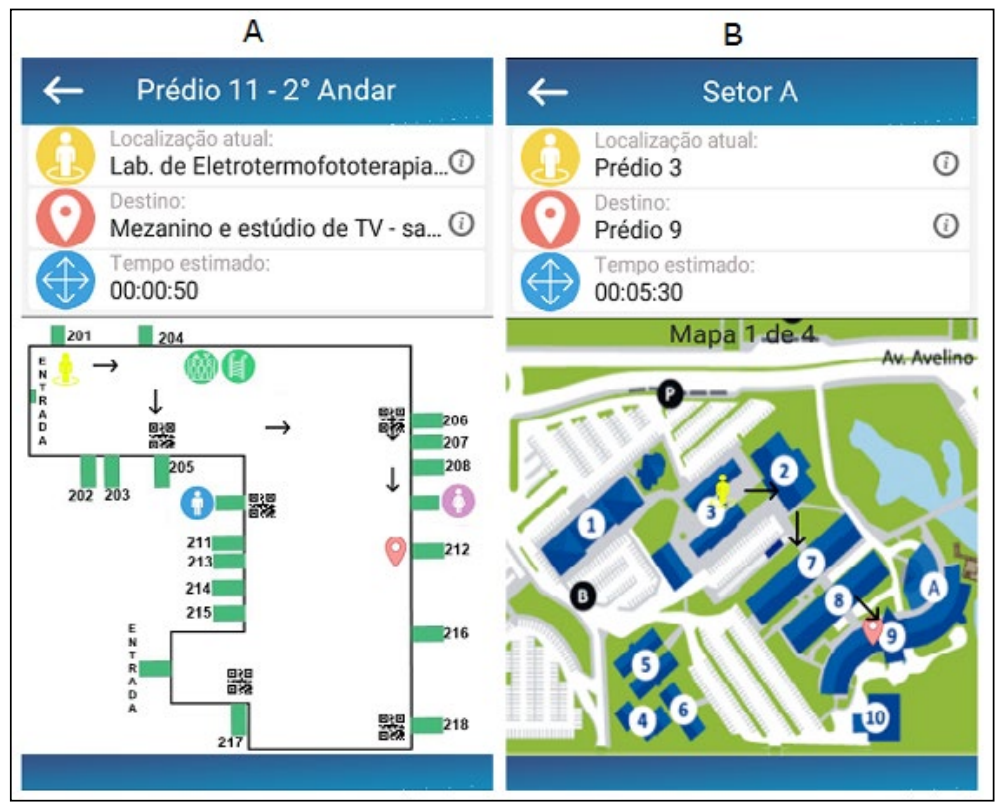

Fonte: Elaborado pelo autor (2017).

Quando o tipo de ambiente do destino é diferente do tipo de ambiente da localização atual as orientações são exibidas da mesma forma que a Figura 5 , imagem B, ou seja, primeiro são exibidas as orientações de como chegar ao prédio do ambiente e caso o local desejado seja um espaço indoor do prédio a imagem utilizada para marcar o destino sobre o mapa conta com uma função. A ação no ícone de destino é identificada no mapa com uma sinalização que utiliza palavras, apresentando a frase "Mapa interno". Quando pressionada a imagem de destino ou a sinalização por palavras, o aplicativo exibe o mapa indoor do destino procurado, por exemplo: a localização atual é o prédio 3 e o destino é a sala 203 do segundo andar do prédio 11. Ao solicitar as orientações, o aplicativo exibe as direções a serem tomadas até o prédio 11 e caso o usuário queira, ao pressionar a marcação de destino sobre o prédio 11, a ferramenta exibe o mapa do segundo andar do prédio 11 com o destino marcado sobre ele, conforme demonstra a Figura 6. 
Figura 6 - Destino sinalizado após uma orientação outdoor

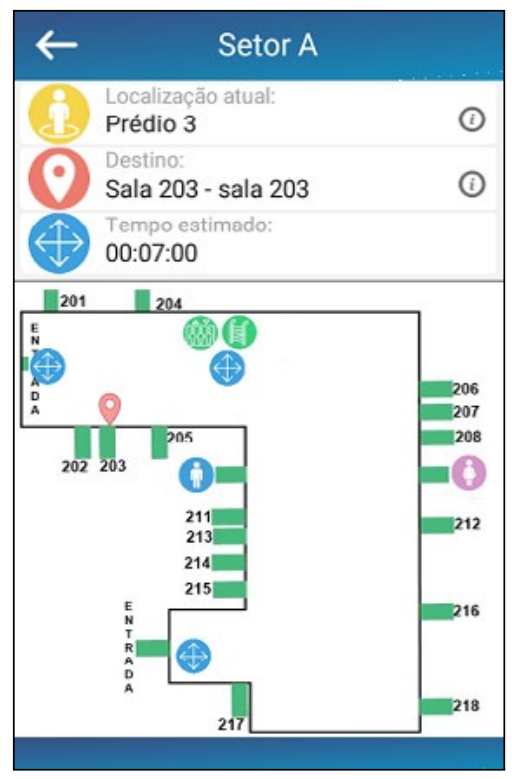

Fonte: Elaborado pelo autor (2017).

Observa-se ainda na Figura 6, que o mapa conta com três ícones iguais ao botão utilizado para solicitar orientações. Estas sinalizações indicam as entradas que o andar possui, ou seja, é possível chegar no segundo andar do prédio 11 por três lugares diferentes, pelas escadas ou elevadores, por uma porta que existe antes da sala 201 e por uma porta que existe perto da sala 217. A imagem utilizada para sinalizar as entradas é a mesma do botão de obter orientações, pois, ao pressionar uma das sinalizações a ferramenta irá buscar o caminho e exibir as orientações de onde o usuário entrou no andar até o destino escolhido, como demonstra a Figura 7, onde o usuário entrou no andar pelas escadas, obtendo as orientações até a sala 203. 
Figura 7 - Orientações após a escolha da entrada no andar

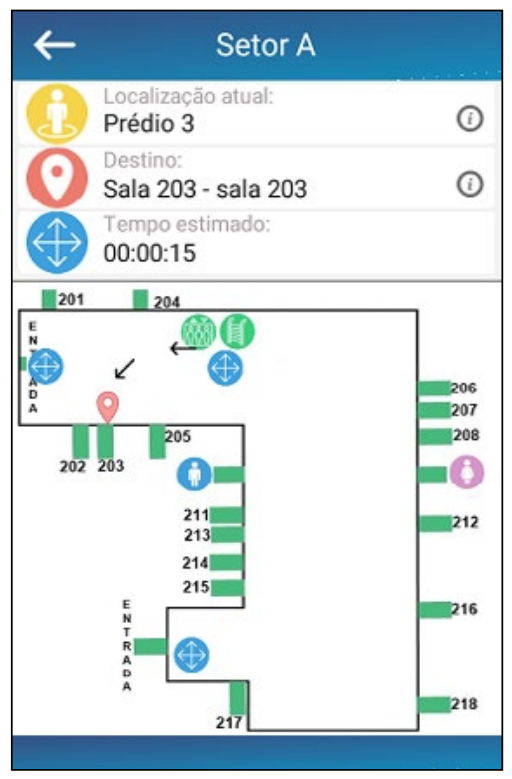

Fonte: Elaborado pelo autor (2017).

Ao buscar orientações dentro do mesmo prédio, porém com a localização e destino de andares diferentes, o software utiliza o segundo tratamento apresentado, exibindo um mapa que demonstra os andares do prédio e sinalizando os andares da localização atual e do destino, onde a imagem que é utilizada para marcar o destino tem o mesmo comportamento que na situação anterior, onde é possível selecionar a imagem ou a sinalização que utiliza palavras, para que o aplicativo exiba o mapa do andar de destino, como demonstra a Figura 30. Na Figura 8 é possível observar a sinalização por palavras, utilizada ao lado do ícone de destino, as orientações fornecidas entre os andares do prédio 11, onde a localização atual é a sala 102 do primeiro andar e o destino escolhido é a sala 404 do quarto andar. 
Figura 8 - Orientação entre os andares de um prédio

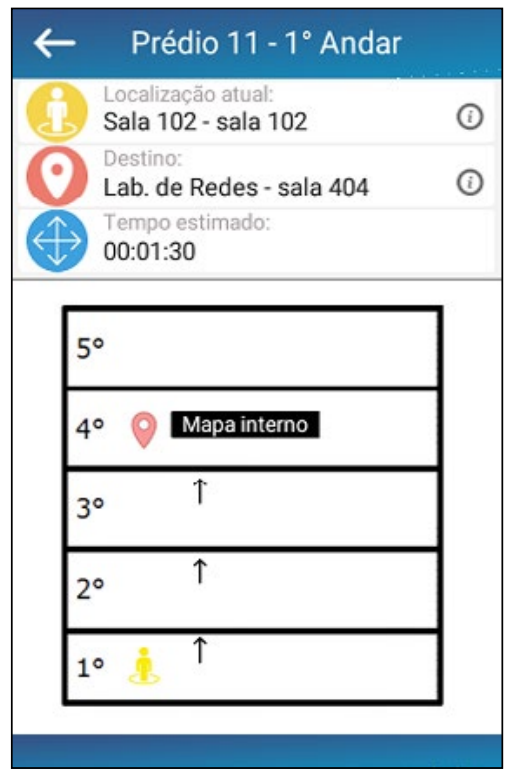

Fonte: Elaborado pelo autor (2017).

\section{VALIDAÇÃO DO EXPERIMENTO}

Após o desenvolvimento da ferramenta FindWay foram realizados alguns testes, cujo objetivo foi validar o software e apontar melhorias para o mesmo. Os testes foram realizados seguindo um roteiro de atividades com cinco tarefas, onde três eram indoor e duas outdoor, sendo executados por dois tipos de perfis de usuários, onde um tipo é considerado como os especialistas, pois seus integrantes possuem um conhecimento maior de software e de aplicativos mobile, e o outro é classificado como usuários finais, pessoas de diferentes áreas de conhecimento, potenciais usuários do aplicativo no seu dia a dia. O teste com usuários finais foi realizado em duas partes, onde na primeira ele foi realizado somente com duas pessoas, sendo denominado como teste piloto e na segunda parte, foram executados mais treze testes, somando um total de quinze.

\subsection{Teste piloto}

Os primeiros testes foram executados por duas pessoas, um homem e uma mulher, ambos estudantes e estagiários na própria instituição. Nos dois casos, foi seguido um roteiro apresentado com cinco passos, onde ambos levaram cerca de 25 a 30 minutos para concluir todas as atividades. Nestes testes, os usuários realizaram as tarefas caminhando pelos andares dos prédios e pelo campus, seguindo as orientações recebidas pelo FindWay. Em ambos, o resultado foi positivo, pois os dois testadores conseguiram chegar em todos 
os destinos procurados, porém, em uma das tarefas da parte outdoor, eles seguiram caminhos diferentes, sendo que um deles era maior que o outro. Depois de concluir todas as tarefas, os usuários responderam um questionário de avaliação do software.

\subsection{Teste com especialistas}

O teste com especialistas foi realizado com quinze alunos da disciplina Interface Humano-Computador (IHC), dos cursos de TI da Univates. Para realizar o teste todos receberam o mesmo roteiro e o executaram em uma sala de aula utilizando os seus dispositivos, sem se deslocar pelos corredores dos prédios ou pelo campus, pois todos já conheciam a estrutura do local e a distribuição de prédios e salas.

Para que fosse possível simular todas as opções de orientação que o aplicativo fornece foram executadas cinco tarefas, sendo que duas delas oferecem uma orientação indoor no mesmo andar, uma entre andares diferentes, uma entre salas de prédios diferentes e a última entre dois prédios diferentes. Para localizar-se, foi utilizado um QR Code com os dados da localização para cada tarefa, onde todos foram lidos com o Smartphone apontando para a tela do computador utilizado pelos testadores. Para os destinos todos utilizaram as listas de locais, com prédios e salas de acordo com as tarefas.

Após a realização das simulações, todos os quinze especialistas responderam um questionário de validação do aplicativo com cinco perguntas, onde três referiam-se à qualidade dos mapas apresentados, das sinalizações sobre os mapas e das orientações exibas para encontrar um destino. A quarta pergunta buscou medir o nível de intuitividade da ferramenta e a quinta, se os especialistas utilizariam ou indicariam o aplicativo para alguém.

Os resultados das cinco perguntas podem ser considerados como regular para a ferramenta, pois deve-se considerar que 53,3\% dos testadores qualificaram os mapas de forma negativa, $26,7 \%$ qualificaram as sinalizações de forma negativa, $60 \%$ classificou as orientações de forma negativa e $53,4 \%$ julgaram o nível de intuitividade como negativo. Nestes percentuais apresentados foram consideradas as respostas das opções "Regular" e "Ruim", onde a opção Regular teve um maior número de respostas em todas as questões.

A quinta pergunta, que questionou se os testadores utilizariam a ferramenta ou indicariam para alguém, oferecia duas respostas, "Sim" e "Não", onde era possível selecionar apenas uma. O resultado desta questão é considerado como positivo para o experimento FindWay, pois as respostas ficaram em $73,33 \%$ para a opção "Sim" e $26,66 \%$ para a opção "Não". Este resultado possivelmente foi obtido pelo fato de os especialistas terem gostado da ideia da ferramenta e por eles conseguirem entender o objetivo do aplicativo. 


\subsection{Validação com usuários finais}

Os testes com os usuários finais foram realizados com alguns voluntários que se disponibilizaram a realizar o roteiro de teste. Neste teste, quinze pessoas executaram o mesmo roteiro dos demais testes já realizados, seguindo o roteiro caminhando pela instituição. Durante a realização das tarefas alguns usuários tiveram dificuldades. A maioria delas foi em relação a orientação dos mapas outdoor e indoor, onde, de acordo com os testadores, em alguns momentos o mapa parecia estar invertido ou de lado. Em alguns casos, os voluntários chegaram a virar o Smartphone para seguir as orientações que o aplicativo FindWay forneceu a eles.

Além da orientação dos mapas, alguns tiveram dificuldades de entender como as listas de locais funcionavam, pois é preciso escolher um prédio e um andar para selecionar uma sala. Com o passar das tarefas do roteiro, todos conseguiram utilizar as listas com mais facilidade. Também foram encontradas outras dificuldades, como: identificar as sinalizações nos mapas, dificuldade em encontrar no mapa por onde entrou no andar e dificuldade em visualizar a numeração das salas por elas serem pequenas.

Após a realização de todas as tarefas, os usuários responderam um questionário de avaliação da ferramenta testada, o mesmo disponibilizado para os dois testadores do teste piloto. Ao todo, eram oito perguntas, onde o objetivo delas era identificar as dificuldades encontradas para realizar o roteiro de testes e verificar a qualidade das orientações fornecidas por ele. Na pergunta número um, os usuários responderam se o software ajudou a encontrar os destinos procurados, e para $93,3 \%$ as orientações disponibilizadas pelo FindWay ajudaram a encontrar o local procurado, e para 6,7\% o aplicativo auxiliou somente um pouco. A questão três verificou se os testadores tiveram alguma dificuldade em utilizar o software, onde $60 \%$ responderam que encontraram algumas dificuldades e $40 \%$ não tiveram.

A pergunta quatro verificou o nível de dificuldade encontrado para definir um destino, onde era preciso utilizar as listas de locais para escolher uma sala ou um prédio. Nesta questão, 66,7\% informaram que o nível de dificuldade foi baixo, 20\% médio e 13,3\% alto. As perguntas cinco, seis, sete e oito, tinham como objetivo principal validar a qualidade dos mapas, das sinalizações sobre os mapas, das orientações fornecidas pela ferramenta e por último, se os testadores voluntários utilizariam o aplicativo FindWay.

Os resultados das perguntas cinco, seis e sete são positivos para a validação da ferramenta, pois o resultado de ambas as perguntas ficou entre muito bom e bom, na maioria das respostas. Por fim, a pergunta número oito mostra que a ferramenta seria utilizada pela maioria dos testadores, sendo que $86,7 \%$ responderam de forma positiva, talvez pelo motivo que, em todos os testes realizados, os usuários conseguiram chegar ao destino final seguindo as orientações do sistema wayfinding disponibilizadas pela ferramenta. 
Além das oito perguntas, o formulário de avaliação do aplicativo FindWay contava com alguns campos para que os testadores informassem o porquê eles utilizariam a ferramenta, os pontos positivos e negativos dela e algumas melhorias. Como justificativa para utilizar o software foi informado: aplicativo fácil de entender e prático; orientação muito boa; auxilia na localização de locais na Univates. Como positivo, foram descritos os seguintes pontos: facilidade em localizar-se e encontrar o destino; ajuda na localização na Univates; facilidade em utilizar o aplicativo; orientações indicam corretamente o trajeto até o destino; bom design; funciona sem utilizar internet. Como pontos negativos foram apontados: orientação dos mapas; ícones de localização pequenos; e falta de pontos de referência nos mapas. Por fim, foram sugeridas as seguintes melhorias: fazer as setas piscarem para destacá-las; melhoria na orientação dos mapas; zoom nos mapas; fazer com que os mapas virem de acordo com os movimentos do Smartphone.

\section{CONSIDERAÇÕES FINAIS}

Com base na pesquisa realizada percebeu-se que atualmente existem inúmeros problemas de localização e orientação nos ambientes indoor e outdoor, principalmente nos locais indoor, pois em alguns casos, não existe uma sinalização adequada para o local e não é possível utilizar um sistema de GPS para orientar-se nestes ambientes. Através do presente estudo, também foi possível perceber que com uma boa sinalização é possível minimizar algumas dificuldades, seja disponibilizando um sistema wayfinding através de placas para oferecer orientações aos usuários ou espalhando mapas pelo local, para que os utilizadores do ambiente consigam localizar-se nele.

Baseado nos problemas dos ambientes indoor e outdoor, este artigo focou em auxiliar as tarefas de localização e mobilidade nestes locais indoor. Este auxílio disponibilizado pela ferramenta desenvolvida, é necessário em grande parte dos ambientes indoor, pois alguns deles são muito grandes e contam com diversas repartições, o que os torna complexos. Com isso a movimentação dos frequentadores do local é prejudicada, pois eles acabam encontrando dificuldades para encontrar o caminho correto para chegar até o que procuram.

Levando em consideração os fatos apresentados nos parágrafos anteriores e que atualmente as pessoas utilizam os seus Smartphones para realizar inúmeras tarefas, a solução desenvolvida no presente trabalho possui um grande público-alvo. Com isso ela pode ser aplicada em diversos lugares para auxiliar na mobilidade indoor, seja em aeroportos ou em um campus de uma universidade, como o campus da Univates, que foi utilizado como estudo de caso do protótipo desenvolvido.

Na visão do autor do presente trabalho, foi utilizada a metodologia correta para a realização deste estudo. Com ela, foi possível atender todos as necessidades da ferramenta e cumprir todas as etapas do estudo, sendo possível 
projetar e desenvolver o protótipo da ferramenta, construir e aplicar um roteiro de testes para validar o aplicativo FindWay e identificar futuras melhorias para o software.

Para confirmar esta visão, pode-se utilizar os resultados dos testes com usuários pelo campus da Univates, onde todos os testadores conseguiram chegar aos destinos buscados, seguindo as orientações disponibilizadas pelo sistema wayfinding que a ferramenta oferece. Outra confirmação que pode ser utilizada e que serve para mostrar que o software possui mercado para um futuro próximo, são as respostas dos usuários finais que testaram a ferramenta, pois a maior parte deles respondeu que utilizaria o aplicativo quando o mesmo fosse disponibilizado como um produto.

Com base nestas confirmações, o aplicativo FindWay foi validado e aprovado pelos usuários que o utilizaram através dos testes realizados. Porém, seria necessário executar mais algumas vezes o roteiro de testes para identificar melhorias necessárias para colocá-lo em funcionamento em algum local e seria fundamental desenvolver algumas melhorias citadas no capítulo anterior, como o aperfeiçoamento do algoritmo de caminho mínimo e a realização de melhorias na usabilidade do sistema. Todos os itens destacados nas melhorias futuras são necessários para que os usuários possam utilizar a ferramenta facilmente e consigam compreender com maior facilidade as orientações e todas as sinalizações dispostas sobre os mapas.

Mesmo com uma série de melhorias necessárias para a ferramenta, foi possível identificar que o uso do aplicativo FindWay seria muito útil para novos estudantes da Univates, pois eles, na maioria dos casos, desconhecem a distribuição de prédios e salas, e com o auxílio do software poderiam consultar e utilizar o sistema wayfinding disponibilizado por ele para encontrar os locais desconhecidos.

\section{REFERÊNCIAS}

CHAMMA, Norberto; PASTORELO, Pedro D. Marcas \& sinalização: práticas em design corporativo. São Paulo: SENAC, 2007.

COSTA, Polyanna P. da. Teoria de grafos e suas aplicações. Universidade Estadual Paulista, Rio Claro, Brasil, 2011. Disponível em: <http://www.rc.unesp.br/tmelo/ diss-polyanna.pdf>. Acesso em: 04 out. 2016.

DEVFURIA. DEVFURIA. Disponível em: <http://www.devfuria.com.br/logica-deprogramacao/recursividade-e-algoritmos-recursivos/>. Acesso em: 28 abr. 2017.

GATTERMANN, Rodrigo L. Buscalivro: Solução móvel para apoio na localização de livros. Centro Universitário Univates, Lajeado, Brasil, 2013. Disponível em <https:/ / www.univates.br/bdu/>. Acesso em 16 ago. 2016. 
GIL, Antonio C. Como elaborar projetos de pesquisa. 4. ed. São Paulo: Atlas, 2002.

PEZZIN, Olivia C. Design de sinalização do metrô de São Paulo: Estudo de caso de sua manutenção. Universidade de São Paulo, São Paulo, Brasil, 2013. Disponível em: <https: / / www.google.com.br/url?sa=t\&rct=j\&q=\&esrc=s\&source=web\&cd=1\&ved=0ahUKEwj7r_3HnNDOAhXBk5AKHeL7BpQQFggfMAA\&url=http $\% 3 \mathrm{~A} \% 2 \mathrm{~F} \% 2 \mathrm{Fwww}$.teses.usp.br\%2Fteses $\% 2 \mathrm{Fdisponiveis} \% 2 \mathrm{~F} 16 \%$ 2F16134\%2Ftde-15012014-143338\%2Fpublico\%2Fdissertacao_olivia_original. pdf\&usg=AFQjCNEWaMFKhpPhEedkwplm8zV61DhL_g\&bvm=bv.129759880,d. Y2I\&cad=rja $>$. Acesso em: 27 ago. 2016.

SEGD. Society for Experiential Graphic Designs. Disponível em: <https:/ /segd.org/ what-wayfinding>. Acesso em: 20 ago. 2016. 